\title{
Comparison on Properties of 3 Anti-corrosive Coating Materials for Outer Protection to Buried Metal Pipe
}

\author{
Yan-Hua Chen ${ }^{1,2, a^{*}}$, Shuo Wang ${ }^{1, b}$, Lin-lin Liu ${ }^{1, c}$, Le Wang ${ }^{1}$ and Jian-nan Li ${ }^{1}$ \\ ${ }^{1}$ North China University of Science and Technology, Tangshan 063009, China \\ ${ }^{2}$ Earthquake Engineering Research Center of Hebei Province, Tangshan 063009, China \\ acyh427@163.com, b445021930@qq.com, '974549693@qq.com \\ ${ }^{*}$ corresponding author
}

\begin{abstract}
Keywords: Anti-corrosive coating material (ACCM), Glass-fiber epoxy, Carbon-fiber epoxy, Visco-elastic material, Buried metal pipe

Abstract. This paper describes an investigation of properties of 3 ACCMs, including cathodic disbonding, hot water dipping in, shear strength and bonding characteristic. According to standards of oil and gas pipeline, some experiments are carried to determine these characteristics. From these experimental results, each has his strong point for 3 ACCMs. Carbon-fiber epoxy is good at resistance on cathode disbonding, but heat-resistance, shear strength and bonding characteristic of visco-elastic material is better. So, carbon-fiber epoxy is fit for buried pipeline with cathodic protection. Visco-elastic material can be used in many cases under the precondition of not over cathodic protection. This research will provide the basis for the selection of anti-corrosive coating material of buried metal pipe in oilfield construction engineering.
\end{abstract}

\section{Introduction}

Buried metal pipes play an important role in transmitting fluid in kinds of areas, such as petroleum industry, chemical industry, and so on. Metal pipes without protection are often corroded. These corroded pipes will cause large damage, for example leakage and blast. Even, oil field production ceases and environment is polluted. Now, in order to protect metal pipe from corrosion, there are some protection methods for inside corrosion and outside corrosion, such as using efficient inhibitors, anti-corrosive coatings, cathodic protection (CP), and several ways connected. $\mathrm{CP}$ is reliable, effective and economic method for protection of a variety of pipelines, especially for cool water system against corrosion [1]. The application of $\mathrm{CP}$ will affect the protective properties of the anti-corrosive coating [2]. Good coating will protect metal pipe from the water permeation, such as HPCC, asphalt cement [3, 4]. Some composite coatings can protect metal pipe from microorganism corrosion [5]. Now, various ACCMs are used in pipe engineering. Properties of these materials are investigated [3-7].

In this paper, 3 ACCMs are selected. According to references [8], some tests are done to investigate properties of 3 materials, including cathodic disbonding, hot water dipping in, shear strength and bonding characteristic. This research will help to select appropriate ACCM for pipeline protecting and repairing under various conditions.

\section{Experiments on material properties}

Considering actual material selection, technology and cost, glass-fiber epoxy, carbon-fiber epoxy and visco-elastic material are selected to investigate their properties by groups of experiments.

Cathodic disbonding. According to standard [8], 3 pipe specimens with $\varphi 89$ are prepared, and are covered with different protection coatings respectively as above mentioned. Man-made holes at the top, the middle, and the bottom of the pipe are set. These pipes are connected with $\mathrm{Mg}$ anode, and immerged in prepared salt solution 45 days. Room temperature is controlled at $18-20^{\circ} \mathrm{C}$, temperature of salt solution is at $20-22^{\circ} \mathrm{C}$. See figure 1 . 


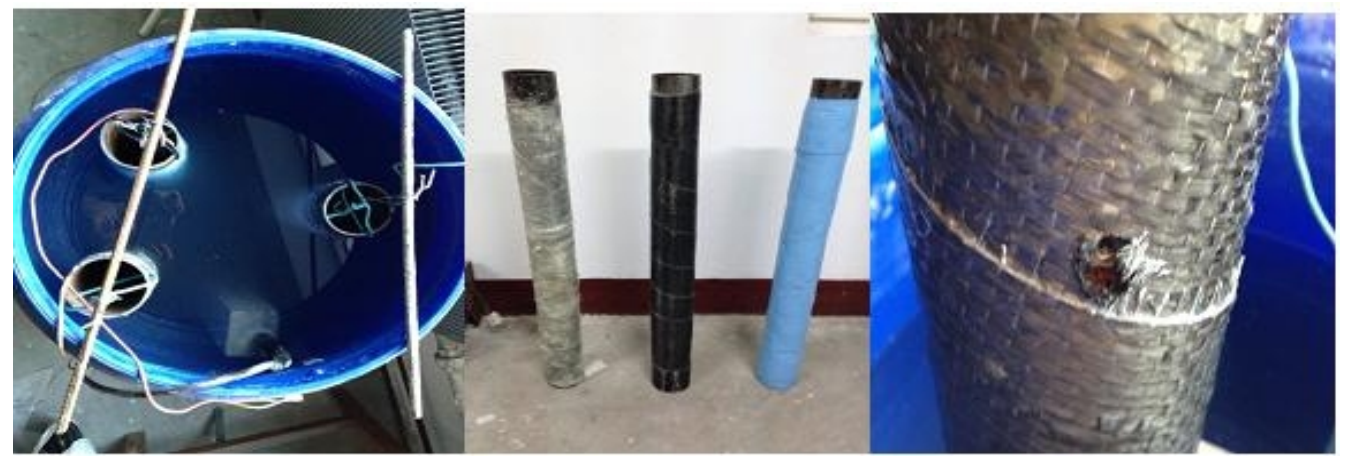

Fig. 1 Experimental process of cathodic disbonding

Dipping in hot water. 3 pipe specimens are prepared to dip in hot water (about $70^{\circ} \mathrm{C}$ ) 45 days, then observe if the coating stratified and if water infiltrated into. See figure 2.

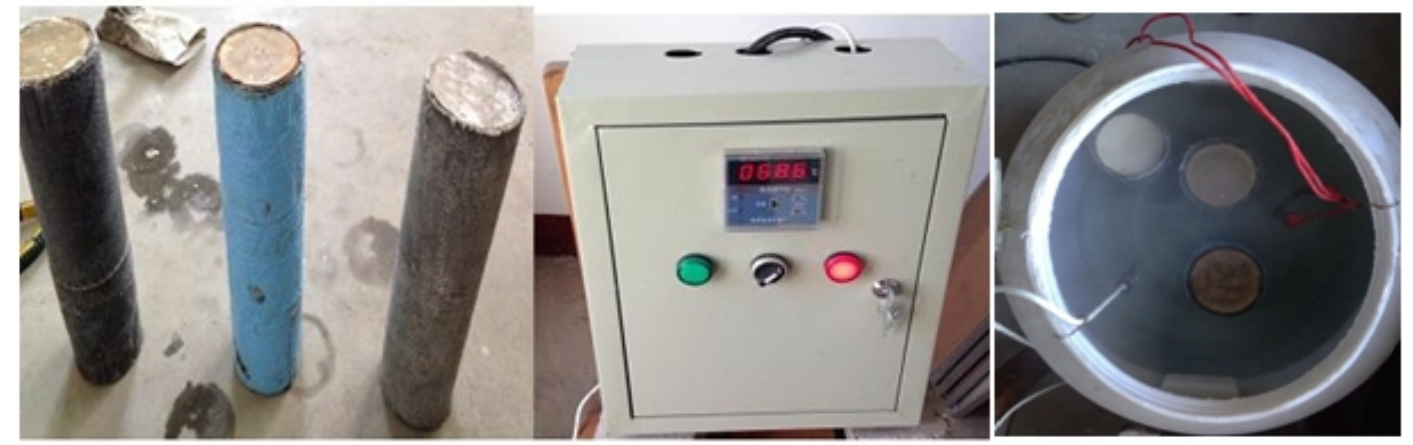

Fig.2 Experimental process of dipping in

Shear strength of coating. Visco-elastic and epoxy materials are used to do 3 groups of shear specimens, then do shear tests by universal test machine. See figure 3.

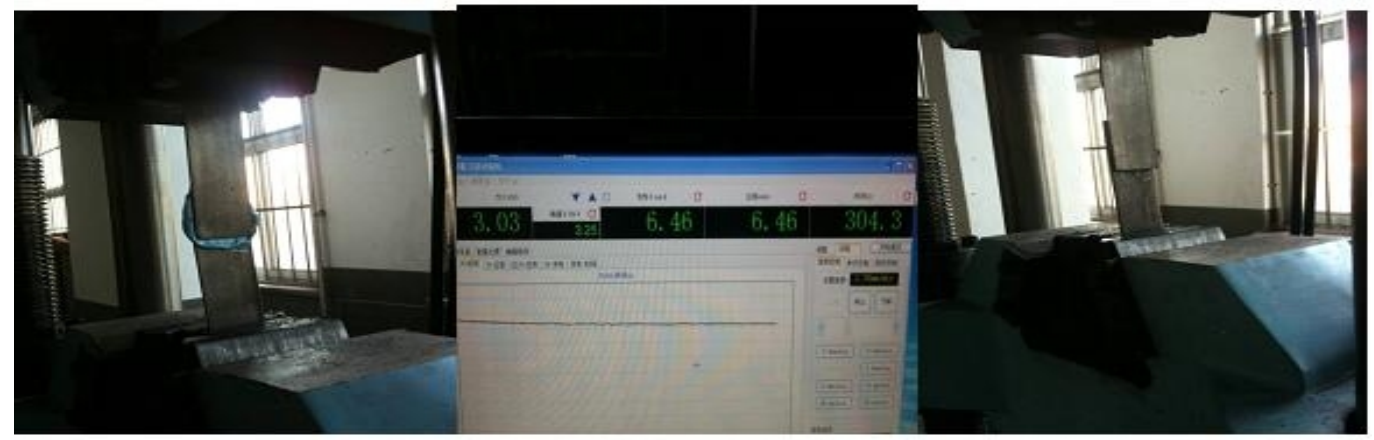

Fig.3 Experimental process of measuring shear strength

Bonding property. Visco-elastic and epoxy materials are used to do bonding specimens, then do bonding test as figure 4 . At the same time, bonding properties of pipes covered with glass-fiber epoxy, carbon-fiber epoxy and visco-elastic ACCM are investigated by bonding tests. See figure 5 .

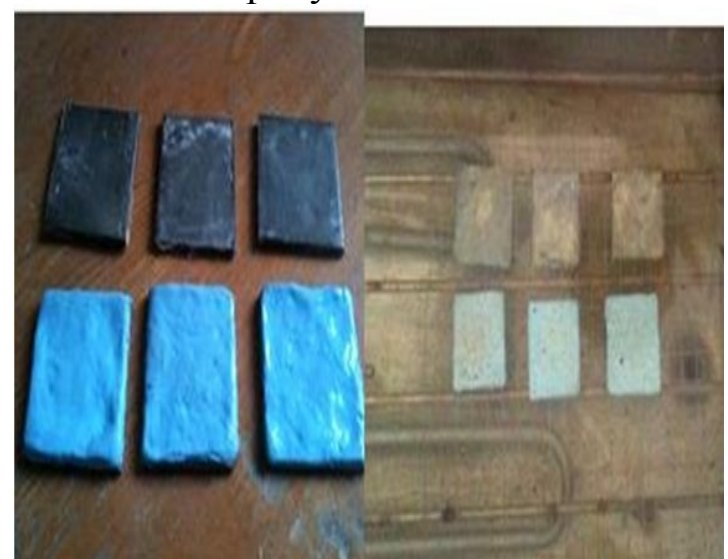

Fig. 4 Experimental process of bonding test of coating material specimens

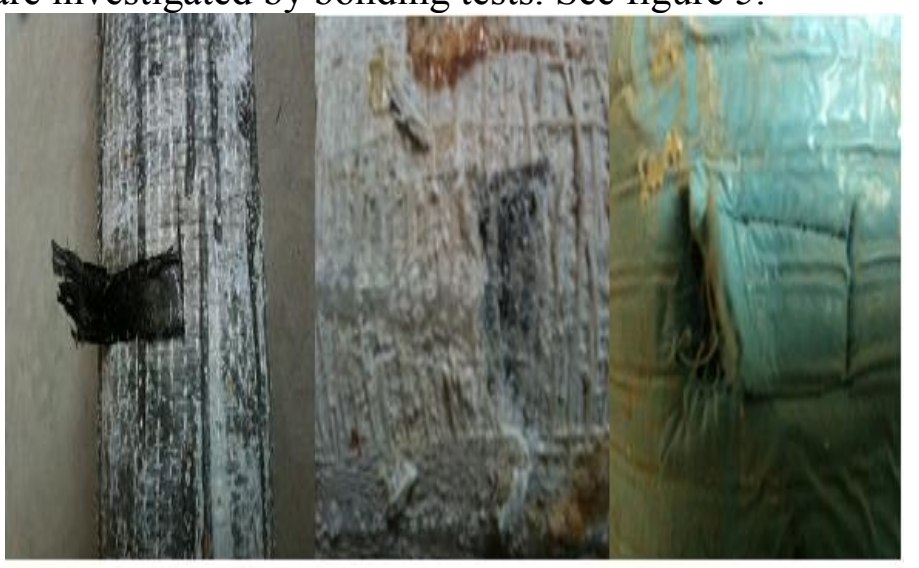

Fig. 5 Experimental process of bonding test of pipes covered ACCM 


\section{Experimental results and discussion}

Cathodic disbonding. When the period of cathodic disbonding test is over, pipe specimens are taken out. It can be seen from figure 6 that surface of carbon-fiber epoxy specimen is rimed with white salt which is obvious near the man-made hole. Because the glass-fiber epoxy specimen is white, salt crystal is not easy to find by eyes. If observed it carefully, salt crystal can be seen on the surface of the glass-fiber epoxy specimen, but no salt crystal on the surface of visco-elastic specimen.

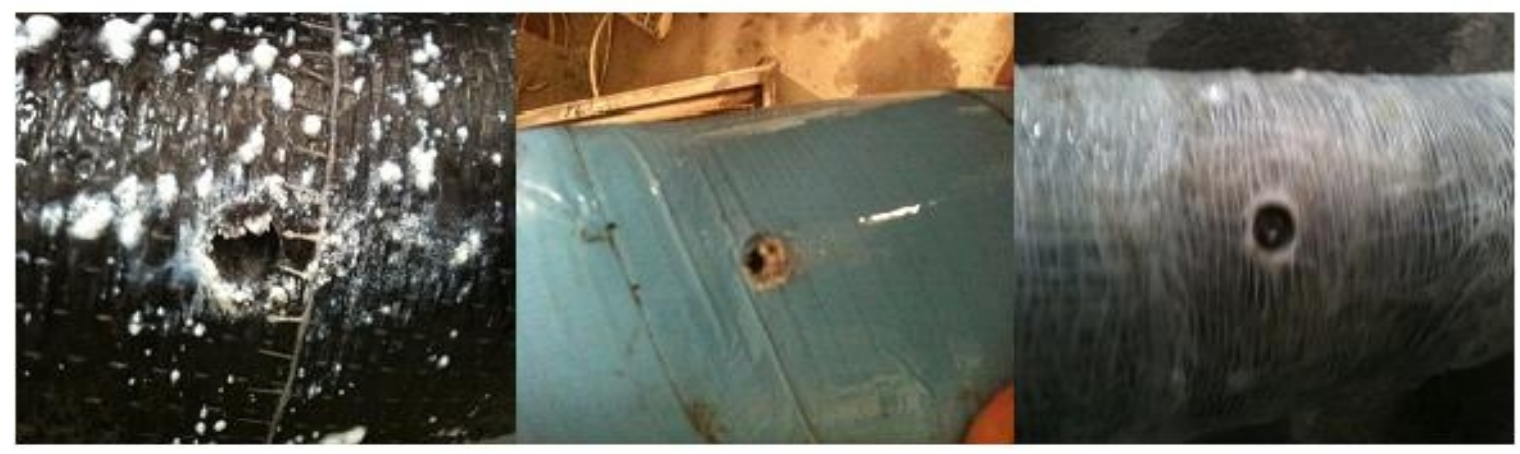

Fig.6 Appearance of specimens after cathodic disbonding test

By incising the specimen of cathodic disbonding (figure 7), disbonding area is calculated as table 1.

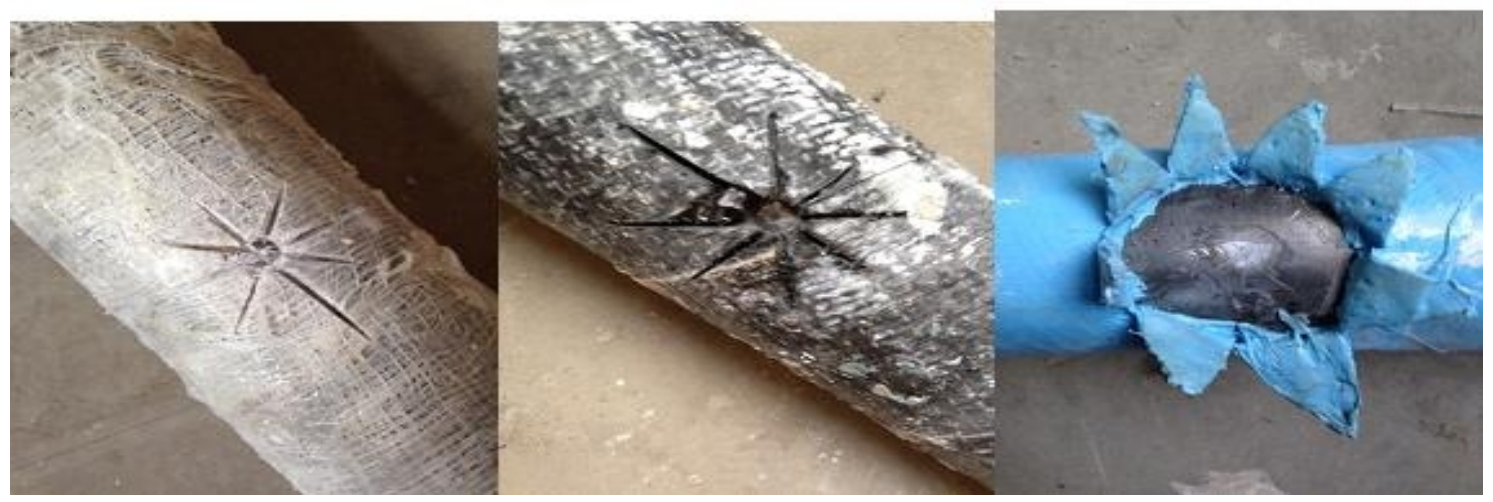

Fig.7 Calculation of disbonding area

Table 1 Area of cathodic disbonding

\begin{tabular}{c|l}
\hline Anti-corrosive coating & Disbonding area $\left(\mathrm{mm}^{2}\right)$ \\
\hline Visco-elastic & 2494.5 \\
\hline Glass-fiber epoxy & 0 \\
\hline Carbon-fiber epoxy & 0 \\
\hline
\end{tabular}

From table 1 and figure 7, resistance abilities to cathodic disbonding of glass-fiber and carbon-fiber epoxy are stronger than visco-elastic material. Under the effect of $\mathrm{Mg}$ anode, bonding forces between the wall of pipe and fiber-epoxy are not affected, and keep strong. But the force between the wall of pipe and visco-elastic material are changed, visco-elastic material is easy to remove from pipe wall. Because the comprehensive properties of composites made by fiber and epoxy are good, they are fit for buried metal pipe with cathodic protection. If visco-elastic material is used in cathodic protection, over protection should be avoided.

Dipping in hot water. During heating period, air bubbles will appear on the surface of glass-fiber and carbon-fiber epoxy specimens, but no air bubbles on visco-elastic specimen, see figure 8. It relates with components of curing agents of epoxy resin. So, solidifying process on epoxy resin should be strengthened. Under high temperature, visco-elastic material can be selected to be protection coating.

Shear strength. Shear strength of visco-elastic material is $0.05 \mathrm{MPa}$, epoxy resin is $0.86 \mathrm{MPa}$. Anti-shear ability of epoxy resin is stronger. Flexibility of visco-elastic material is better.

Bonding property. It can be seen from figure 9 that bonding property of visco-elastic material is excellent compared with epoxy resin. When epoxy resin is connected with glass-fiber and carbon fiber, ACCMs are made. Bonding properties of glass-fiber epoxy and carbon-fiber epoxy are very 
good. From figure 5, glass-fiber epoxy and carbon fiber epoxy coatings are difficult to cut, and to separate with pipeline. Also, visco-elastic material connected with belt shows well bonding property.

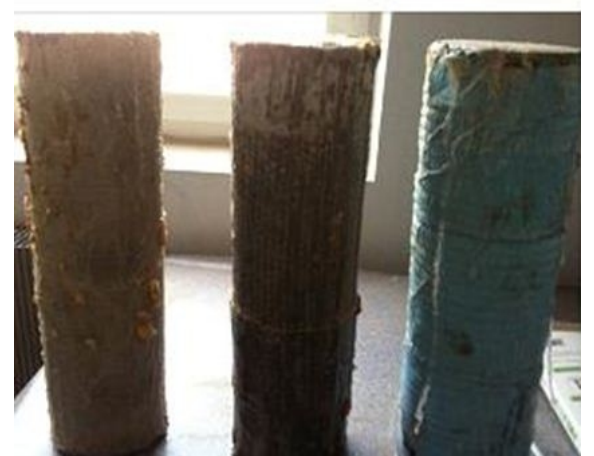

Fig.8 Heating results of three specimens

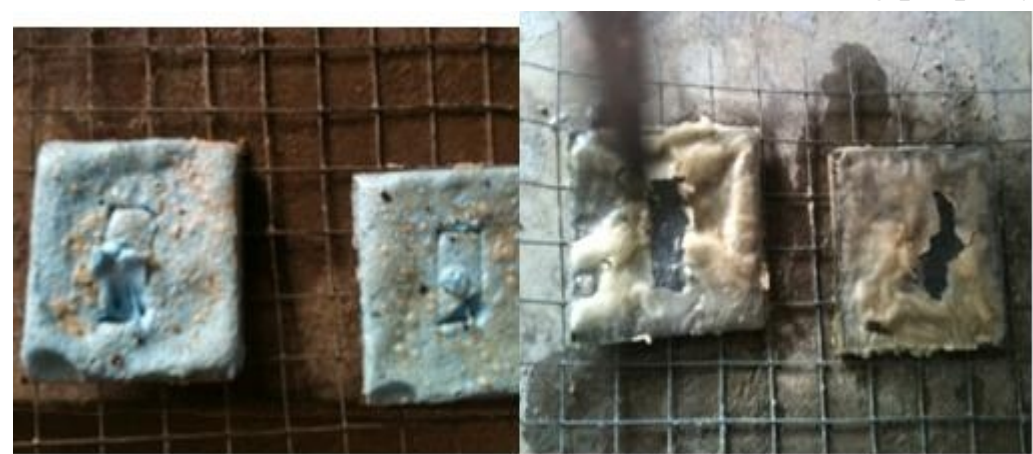

Fig. 9 Bonding situation of visco-elastic material and epoxy resin

\section{Conclusions}

According to the results of these property experiments, we can obtain some conclusions: 1) Resistance abilities to cathodic disbonding of glass-fiber epoxy and carbon-fiber epoxy are stronger than visco-elastic material. Comprehensive properties of composites made by fiber and epoxy are good, glass-fiber epoxy and carbon-fiber epoxy are fit for buried metal pipe with cathodic protection. 2) Bonding property of visco-elastic material is better than pure epoxy resin. But fiber and epoxy resin can be connected to be a good protection coating. 3) Considering anti-corrosive aspect, all these 3 materials can be selected in work site to prevent pipeline from corrosion. In fact, working condition, engineering quantities and costs should be considered synthetically in selecting ACCM. For example, if project period is short, engineering quantities is not very big, fund is enough, visco-elastic coating can be used, because it is easy to operate in working site.

\section{Acknowledgement}

This paper is supported by the National Science Foundation of China(No.51378172) and the Natural Science Foundation of Hebei Province(No.E2014209089).

\section{References}

[1] I.Gurrappa, Cathodic protection of cooling water systems and selection of appropriate materials, Journal of Materials Processing Technology, 166(2005) 256-267.

[2] E.O.Eltai, J.D.Scantlebury, E.V.Koroleva, The effects of different ionic migration on the performance of intact unpigmented epoxy coated mild steel under cathodic protection, Progress in Organic Coatings, 75(2012) $79-85$

[3] A.Q. Fu, Y.F. Cheng. Characterization of the permeability of a high performance composite coating to cathodic protection and its implications on pipeline integrity. Progress in Organic Coatings, 72(2011) 423- 428.

[4] H. AbdEl-Wahab, A.M.M.Saleh, M.A.Wassel. et al. Preparation and evaluation of a new anti-corrosive coating based on asphalt cement blended with polyesteramide resin for steel protection. Progress in Organic Coatings, 76(2013) 1363-1368.

[5] M. Fathy, A. Badawi, A.M. Mazrouaa, et al. Styrene N-vinylpyrrolidone metal-nanocomposites as antibacterial coatings against Sulfate Reducing Bacteria, Materials Science and Engineering C, 33(2013) 4063-4070.

[6] Y.H.Zhang, X.Y.Zhang, J.H.Yuan. Analysis of Standard and Technical Parameters of Viscoelastic Tape, Corrosion \& Protection, 8(2013)730-733,759. (in Chinese)

[7] M.K. Madhup, N.K. Shah, P.M. Wadhwani. Investigation of surface morphology, anti-corrosive and abrasionresistance properties of nickel oxide epoxy nanocomposite (NiO-ENC)coating on mild steel substrate[J]. Progress in Organic Coatings 80 (2015) 1-10. 
[8] The People's Republic of China Petroleum and natural gas industry standards. SY/T 0037-2012 Beijing, Petroleum Industry Press, 2012. 